\title{
Erratum to: The Organizational Account of Function is an Etiological Account of Function
}

\author{
Marc Artiga' ${ }^{1}$ Manolo Martínez ${ }^{2}$
}

Published online: 24 July 2015

(C) Springer Science+Business Media Dordrecht 2015

\section{Erratum to: Acta Biotheor \\ DOI 10.1007/s10441-015-9256-X}

In the original publication of the article, we have some names of definitions that should go in bold letters. Furthermore, the whole definition should be indented.

The correct version is as follows:

\section{Page 2}

The Etiology of Wings: The actual existence of B's wings is explained by wings having helped B's ancestors to fly in the (comparatively recent) past.

Etiological Function: A trait $\mathrm{T}$ has the function of producing an effect of type $\mathrm{E}$ in an organism $\mathrm{O}$ if and only the following fact contributes, in the relevant way, to a causal explanation that $\mathrm{T}$ is in $\mathrm{O}$ : $\mathrm{T}$ has contributed to the fitness of O's ancestors (in the comparatively recent past) by producing effects of type E.

Page 5

Organizational Function: A trait type $\mathrm{T}$ has a function if, and only if, it is subject to organizational closure $\mathrm{C}$ in a differentiated self-maintaining system $\mathrm{S}$.

The online version of the original article can be found under doi:10.1007/s10441-015-9256-x.

Marc Artiga

marc.artiga@gmail.com

1 Munich Center for Mathematical Philosophy, Ludwig-Maximilians-Universität München, Geschwister-Scholl-Platz 1, 80539 Munich, Germany

2 LOGOS - Logic, Language and Cognition Research Group, Universitat Autónoma de Barcelona, Cerdanyola del Valles, Barcelona, Spain 
This definition implies the fulfillment of three different conditions. Accordingly, a trait $\mathrm{T}$ has a function if and only if:

C1 $\mathrm{T}$ contributes to the maintenance of the organization $\mathrm{O}$ of $\mathrm{S}$;

$\mathrm{C2} \mathrm{T}$ is produced and maintained under some constraints exerted by $\mathrm{O}$;

C3 S realizes organizational closure. (Mossio et al. 2011, p. 594)

Page 8

\section{Function Grounding OA:}

(C1) Donkey semen has contributed to the maintenance of the organization of a donkey lineage (by aiding donkey reproduction across generations),

(C2) Semen is maintained and produced by this organization (say, its way of being a lineage, in which some individuals are parents or offspring of others. ${ }^{1}$ )

The Etiology of Semen: The actual existence of this donkey's semen is explained by semen having helped the donkey's ancestors to reproduce in the (comparatively recent) past.

\footnotetext{
${ }^{1}$ Again, the claim about organizational differentiation is disputable, but we will simply grant it for the sake of the argument. 